Mamad Ahmad dan Asep Supriadi: Konservasi Alam dalam Novel Kekal Karya Jalu...

\title{
KONSERVASI ALAM DALAM NOVEL KEKAL KARYA JALU KANCANA (KAJIAN EKOKRITIK)
}

\author{
Natural Conservation in Novel Kekal by Jalu Kancana (Ecocritic Study) \\ Mamad Ahmad dan Asep Supriadi \\ Balai Bahasa Jawa Barat \\ Jalan Sumbawa No. 11, Bandung, Indonesia \\ Pos-el: mhads2016@gmail.com
}

Naskah masuk: 19 Agustus 2020; disetujui: 8 Desember 2020; revisi akhir: 18 Desember 2020

\begin{abstract}
Abstrak
Novel Kekal karya Jalu Kancana menceritakan kegiatan eksploitasi yang dilakukan oleh perusahaan tambang panas bumi di Kawasan Cagar Alam Kamojang. Eksploitasi berdampak pada kerusakan alam dan kepunahan kekayaan flora dan fauna yang selama ini menjadi bagian keragaman hayati dunia. Penelitian ini membahas kerusakan dan upaya yang dilakukan oleh konservasionis terhadap kerusakan alam. Penelitian ini bertujuan untuk mendeskripsikan bentuk kerusakan hutan dan perjuangan kaum konservasi dalam menjaga dan melestarikan hutan berdasarkan kajian ekokritik Greg Garrard. Metode analisis data yang digunakan dalam penelitian ini adalah interpretasi dan pemahaman dengan analisis konten. Sumber data penelitian ini ialah novel dengan judul Kekal karya Jalu Kancana yang diterbitkan oleh Buku Mojok di Sleman Yogyakarta tahun 2019. Hasil analisis menunjukkan dampak dari eksploitasi telah mengakibatkan kerusakan hutan secara masif di sebagian wilayah hutan Indonesia umumnya dan Kawasan Cagar Alam Kamojang pada khususnya. Perlawanan yang dilakukan bersifat ideologis melalui tulisan yang kritis terhadap pemerintah.
\end{abstract}

Kata kunci: ekokritik, novel Kekal, hutan, konservasi, alam

\begin{abstract}
Novel Kekal by Jalu Kancana tells about the exploitation activities carried out by a geothermal mining company in the Kamojang Nature Reserve. Exploitation has an impact on the destruction of nature and the extinction of flora and fauna that have been part of the world's biodiversity. This study discusses the damage and efforts made by conservationists. This study aims to describe the form of forest destruction and the struggle of conservationists in protecting and conserving forests based on Greg Garrard's ecocritical study. The data analysis method used in this research is interpretation and understanding with content analysis. The data source for this research is a novel entitled Kekal by Jalu Kancana, published by Buku Mojok in Sleman Yogyakarta in 2019. The results of the analysis show that the impact of exploitation has resulted in massive forest destruction in parts of Indonesia's forest in general and in the Kamojang Nature Reserve in particular. Therefore, there are efforts made by conservationists to restore forest harmony.
\end{abstract}

Keywords: ecocritic, novel Kekal, forest, conservation, nature

\section{PENDAHULUAN}

Kekal merupakan sebuah novel karya Jalu Kancana yang diterbitkan oleh Buku Mojok tahun 2019. Selain bercerita tentang upaya konservasi alam yang dilakukan oleh relawan Save Ciharus dan relawan lain di wilayah Sumatra, novel Kekal juga menceritakan percintaan seorang anggota relawan Save Ciharus, Alit dengan pacarnya yang bernama Renata. Sastra dengan alam sekitar merupakan dua hal yang memiliki hubungan timbal balik. Banyak sastrawan yang menjadikan alam sebagai media inspirasi untuk menghasilkan sebuah karya sastra. Endraswara (dalam Laily, 2015) mengatakan bahwa sastra membutuhkan alam sebagai inspirasinya dan alam 
Mamad Ahmad dan Asep Supriadi: Konservasi Alam dalam Novel Kekal Karya Jalu...

membutuhkan

sastra

sebagai

konservasinya.

Konservasi alam dilakukan sebagai upaya untuk menjaga kelestarian alam. Kelestarian alam akan terwujud apabila flora dan fauna terjaga dengan baik. Hutan yang lestari memberikan kita penghidupan. Oleh karena itu, seyogyanya kita harus menjaga dan merawat hutan serta lingkungan sekitar agar tetap lestari. Kelestarian hutan dan lingkungan diperlukan sebagai salah satu upaya untuk menjaga keseimbangan alam sehingga mampu meminimalisasi bencana alam. Namun, fakta menunjukkan banyak di antara kita yang merambah kekayaaan alam tanpa memperhitungkan akibat dari tindakan tersebut.

Eksploitasi alam yang semakin gencar dilakukan oleh oknum-oknum tidak bertanggung jawab di beberapa daerah sebagai akibat dari keserakahan manusia terhadap kekayaan alam yang melimpah. Eksploitasi tanpa diimbangi dengan upaya penanaman kembali (reboisasi) menjadikan hutan kita gundul. Hal ini berakibat pada ketitidakmampuan area tersebut menjadi media resapan air sehingga ancaman bencana terjadi di mana-mana. Mahayana (dalam Uniawati, 2014) mengatakan bahwa kesadaran manusia terhadap lingkungan telah lama dikumandangkan oleh sastrawan dalam karya-karyanya. Harmonisasi alam dan manusia sangat dibutuhkan sebagai upaya untuk menjaga kelestarian dan kelangsungan hidup manusia itu sendiri.

Karya sastra dengan tema lingkungan lahir dari sastrawan yang memanfaatkan alam sebagai sumber inspirasi. Penulis menjadikan alam sebagai media untuk memberikan gambaran suasana yang melatarbelakangi cerita dalam karya tersebut. Novel merupakan salah satu karya sastra yang dapat merepresentasikan kondisi lingkungan dan persfektif masyarakat terhadap kondisi lingkungan itu sendiri. Representasi yang tersirat dalam novel dapat ditelaah dengan kajian ekokritik.

Novel Keka/ merupakan salah satu novel yang menggunakan alam sebagai latar fisik. Kerusakan flora dan fauna yang diakibatkan oleh eksploitasi tambang digambarkan dengan jelas dalam novel ini. Kondisi alam yang digambarkan dalam novel Kekal menarik untuk dikaji dengan menggunakan teori ekokritik. Ekokritik sebagai satu bidang kajian sastra dengan lingkungan hidup sebagai fokus kajiannya.

Penelitian ini bertujuan untuk mendeskripsikan bagaimana bentuk kerusakan alam dan perlawanan tokoh berdasarkan kajian ekokritik Greg Garrard. Menurut Croall dan Rankin (dalam Harsono, 2008), ekologi merupakan rangkaian ilmu alam, ilmu sosial, filsafat, dan pengetahuan secara menyeluruh. Pendekatan holistik yang menjadikan ilmu ini luas. Akan tetapi, pada dasarnya, ilmu ini membahas saling ketergantungan semua makhluk hidup. Selanjutnya, Harsono (2008) mengatakan bahwa teori ekologi dapat digunakan sebagai alat untuk menyampaikan kritik sehingga penggabungannya dengan teori sastra melahirkan sebuah kajian, yaitu ekokiritik.

Istilah ekokritik berasal dari bahasa Inggris ecocriticism yang terbentuk dari kata ecology dan criticism. Ekologi menurut Kamus Besar Bahasa Indonesia Daring adalah ilmu tentang hubungan timbal balik antara makhluk hidup dan alam sekitarnya. Kritik adalah penilaian atau tanggapan tentang baik buruk suatu hal. Dengan demikian, ekokritik adalah kritik yang berkaitan dengan lingkungan. Glotfelty dan Fromm (Aulia, Juanda, \& Saguni, 2019) mendefiniskan ekokritik sebagai studi tentang hubungan antara sastra dan kondisi fisik lingkungan sekitar. Selanjutnya, Harsono (2008) mengatakan bahwa teori ekokritik merupakan pendidikan tentang pemahaman lingkungan melalui sastra.

Greg (2004) mengatakan bahwa pemahaman akan pengetahuan ekologi tidak sebatas pada harmonisasi dan stabilitas lingkungan, tetapi juga mengetahui sikap dan perilaku manusia terhadap lingkungan sendiri.

Harmonisasi atau keselarasan akan terjaga dengan baik apabila manusia sebagai makhluk yang berakal mampu merawat alam sekitar dengan baik dan penuh tanggung jawab. Tidak semua manusia memiliki perilaku yang baik terhadap alam. Ada di antara kita yang 
Mamad Ahmad dan Asep Supriadi: Konservasi Alam dalam Novel Kekal Karya Jalu...

memanfaatkan alam dengan dalih untuk memenuhi kebutuhan hidup tanpa memedulikan kelestarian alam itu sendiri. Mereka membabat hutan, mengeruk kekayaan alam dengan berbagai macam eksploitasi tanpa memikirkan akibat yang akan terjadi. Namun, tidak sedikit dari mereka juga mencoba untuk menjaga dan melestarikan alam sebagai upaya untuk mencegah bencana alam dan untuk kelangsunagn hidup generasi yang akan datang (Laily, 2015).

Ekokritik merupakan pemikiran atau pendapat yang berpandangan bahwa alam merupakan bagian yang tidak terpisahkan dari kegiatan eksploitasi yang dilakukan oleh manusia itu sendiri untuk kepentingan ekonomi dan politik. Dengan begitu, ekokritik dapat didefinisikan sebagai hubungan sastra dan lingkungan fisik sebagai akibat krisis lingkungan global serta upaya penanggulangan secara praktis dan teoretis (Dewi, 2014).

Sementara itu, Pranoto (dalam Apriliadi, 2018) mengatakan bahwa ekokritik merupakan teori kritis yang digunakan untuk mengkaji hubungan antara manusia dan lingkungan sekitar beserta aspek yang mendukung. Hubungan tersebut tidak sebatas mencari dan mengidentifikasi, tetapi lebih mengarah pada pemberian sugesti kepada pembaca untuk peduli terhadap lingkungan. Oleh karena itu, ekokritik tidak hanya bertujuan untuk menjaga lingkungan, tetapi juga menjaga keselamatan bumi. Selain itu, Juanda (2018) mengatakan bahwa teori ekokritik merupakan kolaborasi antara sastra dan ekologi.

\section{METODE PENELITIAN}

Metode yang digunakan dalam penelitian ini adalah metode kualitatif deskriptif. Sumber data penelitian adalah novel Kekal karya Jalu Kancana diterbitkan oleh Buku Mojok tahun 2019. Data yang diperoleh dari novel tersebut berupa kata, frasa atau kalimat yang berhubungan dengan masalah lingkungan dan hubungannya dengan manusia yang sesuai dengan masalah yang diteliti.

Teknik baca dan catat dilakukan dalam penelitian ini.Teknik baca, dilakukan dengan membaca berulang-ulang novel
Kekal karya Jalu Kancana dengan tujuan menemukan satuan bahasa yang berhubungan dengan rumusan masalah penelitian. Teknik catat, dilakukan untuk mempermudah penulis melakukan analisis data. Teknik analisis data dilakukan untuk merepresentasikan dan menginterpretasikan alam yang terdapat dalam novel Kekal karya Jalu Kancana. Adapun langkah-langkah analisis data dalam penelitian ini adalah sebagai berikut. Penulis membuat dua tabel data. Tabel berisikan nomor, kutipan data atau teks dari novel, dan keterangan (inti dari penelitian yang akan dipaparkan dalam pembahasan). Kedua, kedua tabel disiapkan sesuai pengelompokkan rumusan masalah. Langkah ketiga, mendeskripsikan data-data yang telah dikumpulkan dan terakhir membuat simpulan analisis data novel Kekal karya Jalu Kancana dengan menggunakan teori ekokritik Greg Garrard yang fokus terhadap persoalan lingkungan.

\section{HASIL DAN PEMBAHASAN}

\subsection{Kerusakan Alam}

Pada dasarnya, krisis lingkungan dibedakan menjadi dua bagian. Pertama, bencana yang diakibatkan oleh perilaku buruk manusia terhadap alam lingkungannya, polusi udara, polusi air, radiasi nuklir yang mengakibatkan pemanasan global. Kedua, bencana yang diakibatkan oleh aktivitas alam itu sendiri, seperti gempa bumi, tsunami, erupsi gunung merapi (Yasser, 2014).

Bencana alam datang silih berganti sebagai akibat ulah manusia yang tidak ada hentinya dalam mengeksploitasi alam guna memenuhi kebutuhan hidupnya. Eksploitasi tanpa dibarengi dengan reboisasi mengakibatkan keseimbangan alam terganggu sehingga merusak ekosistem seharusnya dijaga dan dilestarikan. Dibutuhkan kesadaran manusia dalam memahami dan mengayomi alam sekitar untuk meminimalisasi bencana yang akan terjadi sebagai akibat murka alam.

Kerusakan alam yang terjadi di kawasan cagar alam merupakan bentuk eksploitasi alam yang diakibatkan oleh keserakahan manusia. Kawasan yang harusnya steril dari kegiatan manusia karena sebagai 
Mamad Ahmad dan Asep Supriadi: Konservasi Alam dalam Novel Kekal Karya Jalu...

permukiman flora dan fauna seyogyanya masih memiliki kondisi alami dan belum terganggu oleh aktivitas manusia. Cagar alam yang menjadi pusat peradaban bagi hewan dan tumbuhan terancam berganti menjadi kawasan wisata/ekonomi.

Kerusakan hutan yang terjadi di wilayah Cagar Alam Kamojang disebabkan oleh kegiatan survei sebuah perusahaan pertambangan panas bumi untuk membuka lahan tambang baru.

\footnotetext{
"Salah satu camera trap yang kita pasang, secara enggak sengaja merekam beberapa orang yang tengah survei di pinggiran danau."

"Survei? Survei apa?"

"Kita semua tahu, kan, di luar Kawasan Cagar Alam Kamojang itu ada perusahaan P yang kelola tambang panas bumi?" aku mengangguk.

"Direktur utama perusahaan $\mathrm{P}$ sama timnya itu, enggak sengaja terekam waktu mereka survei buat lokasi pembukaan lahan pertambangan di Ciharus!" (Kancana, 2019, p. 55)
}

Eksplorasi yang dilakukan oleh perusahaan $\mathrm{P}$ dengan tujuan pembukaan lahan tambang baru merupakan sebuah ancaman bagi Kawasan Cagar Alam Kamojang. Pada dasarnya, tidak diperbolehkan mengadakan kegiatankegiatan yang bisa merusak lingkungan alam itu sendiri di dalam kawasan cagar alam. Seperti yang telah diatur dalam Undang-Undang No. 5 Tahun 1990 tentang Konservasi Sumber Daya Alam Hayati dan Ekosistemnya pasal 19 ayat 1 yang menyatakan bahwa setiap orang dilarang melakukan kegiatan yang dapat mengakibatkan perubahan terhadap keutuhan suaka alam (Indonesia \& Indonesia, n.d.).

Endraswara (dalam Laily, 2015) menyatakan bahwa keserakahan manusia dalam memenuhi kepentingan ekonomi menjadi penyebab utama kerusakan alam. Secara terus-menerus, mereka mengeksploitasi alam sehingga keseimbangan alam terganggu.

Kegiatan tersebut menunjukkan bahwa sikap pengusaha tambang yang tidak baik karena kegiatan membuka lahan tambang akan berdampak negatif terhadap lingkungan sekitar. Kita tidak akan lagi melihat pohon-pohon sebagai penyimpan/penyerap air, penetralisasi /penyaring udara, serta tempat hinggap burung-burung yang berkicau menambah asri lingkungan.

\begin{abstract}
"Ini gawat, Pep. Di hutan itu ada hewanhewan langka, hewan-hewan dilindungi. Ada hutan-hutan yang menahan banjir ke wilayah Garut. Ada danau penyedia air alami" (Kancana, 2019, p. 56).
\end{abstract}

Eksploitasi kawasan hutan lindung yang dilakukan perusahaan tambang mengakibatkan pencemaran lingkungan. Hal ini tidak hanya mengancam kehidupan manusia, tetapi habitat hewan dan tumbuhan juga. Deforestasi atau dampak kerusakan hutan bagi lingkungan hidup dapat menimbulkan berbagai macam bencana. Kekeringan disebabkan karena perubahan iklim yang ekstrem sebagai akibat produksi oksigen yang minim sementara jumlah karbon dioksida yang dilepaskan udara semakin besar. Selain itu, deforestasi juga mengakibatkan siklus air jadi terganggu.

Pohon-pohon yang berfungsi sebagai penyerap curah hujan dan menghasilkan uap air yang kemudian dilepaskan ke atmosfer. Dengan kata lain, semakin sedikit jumlah pohon, maka kandungan uap air yang akan kembali ke tanah dalam bentuk hujan juga sedikit. Oleh karena itu, Ciharus yang tidak lagi berstatus sebagai cagar alam memiliki dampak terhadap masyarakat. Lambat laun, masyarakat akan merasakan dampak ini, seperti kualitas air yang dikelola oleh PDAM akan menurun atau bahkan kering sama sekali sehingga hanya pipa-pipa kosong yang ada. Wilayah kota Garut juga akan diterjang banjir hebat. Selain itu, habitat macan dan owa Jawa yang bersandar hidup di hutan Ciharus akan puna pada akhirnya.

\subsection{Perlawanan Tokoh Utama terhadap Kerusakan Hutan}

Perlawanan yang dimaksud dalam penelitian ini adalah perlawanan yang dilakukan oleh tokoh Alit dengan "Save Ciharus"-nya di Cagar Alam Kamojang Garut. 
Mamad Ahmad dan Asep Supriadi: Konservasi Alam dalam Novel Kekal Karya Jalu...

Perlawanan "Save Ciharus" di Kamojang, Garut, Jawa Barat yang dimotori oleh Alit dan kawan-kawan merupakan bentuk kepedulian atas fungsi Kawasan Cagar Alam Kamojang dan Papandayan yang beralih fungsi menjadi Taman Wisata Alam melalui SK 25 yang dikeluarkan oleh Kementerian Lingkungan Hidup dan Kehutanan yang menaungi BBKSD sebagai Lembaga Pengelola Sumber Daya Alam. Dengan keluarnya SK 25 tersebut, Alit dan rekan di "Save Ciharus" merasa khawatir akan dampak yang akan terjadi terhadap kondisi kawasan cagar alam yang selama ini menjadi permukiman bagi flora dan fauna yang ada di kawasan tersebut.

Pertambangan panas bumi yang berada di luar kawasan cagar alam diperluas sampai kawasan cagar alam itu sendiri sebagai keserakahan manusia akan kebutuhan ekonomi. Hal ini dilakukan tanpa memperhatikan ekologi sebagai kebutuhan dasar manusia. Di hutan sana, hidup berbagai macam hewan-hewan langka dan dilindungi, tumbuh-tumbuhan, penyerap air yang berfungsi sebagai penyimpan air kala musim kemarau dan penahan banjir ketika musim penghujan, serta danau sebagai penyedia air. Hal tersebut diungkapkan seperti dalam kutipan berikut ini.

Surat tersebut menjelaskan bahwa Kawasan Cagar Alam Kamojang dan Papandayan diturunkan fungsinya menjadi taman wisata alam. Telah diresmikan semenjak satu tahun yang lalu tanpa pemberitahuan kepada siapa pun, termasuk kepada penggiat alam bebas (Kancana, 2019, p. 57).

Alit berjuang supaya SK 25 dicabut agar perusahaan $\mathrm{P}$ tidak merusak atau memusnahkan rumah hewan langka di Kamojang dan Papandayan. Dengan keluarnya SK 25 tersebut, secara tidak langsung, pemerintah telah turut andil dalam perusakan hutan. Selain itu, argumen-argumen oknum akademisi bayaran yang memperkuat pengeluaran SK 25.

Alit dan kawan-kawan seperjuangan melakukan penelitian bandingan yang lebih autentik dari LIPI dan universitas di Bogor, yaitu penelitian yang mampu mematahkan argumen-argumen mereka. Perusahaan dengan mudah membungkam dan membayar oknum-oknum intelektual agar berpihak kepada perusahaaan sehingga keluarlah SK 25 tersebut.

Alit mencari dukungan kepada kelompok pencinta alam di wilayah Sumatra. Mereka bersama-sama melakukan perlawanan terhadap perusahaan-perusahaan yang telah melakukan eksploitasi kawasan hutan lindung menjadi kawasan industri perkebunan oleh perusahaan asing. Kawasan yang dahulu merupakan hutan lindung kini berubah menjadi lahan kopi dan karet. Selain itu, ada eksploitasi kawasan hutan yang dijadikan lahan garapan pertambangan pabrik semen. Perlawanan yang mereka lakukan tidak berbentuk kekerasan fisik, tetapi dalam bentuk konservasi. Hal tersebut digambarkan dalam kutipan berikut ini.

Kubongkar semua yang ada di sana. Buku itu segera kuburu karena segera saja terbersit dalam pikiranku bahwa IUCN merupakan organisasi besar berskala internasional. Aku yakin orang-orang penting yang berada di Sumatra itu mampu membantu kondisiku. Orang-orang konservasi yang dahulu pernah membantu kakek pasti memiliki kekuatan yang jauh melampaui kekuatanku! Aku yakin itu! (Kancana, 2019, p. 41).

Upaya pelestarian lingkungan dilakukan melalui kampanye "Sadar Kawasan". Para penggiat pencinta alam dan konservasionis mengundang awak media untuk mewartakan perlawanan mereka terhadap perusahaan yang telah mengeksploitasi hutan melalui kegiatan free solo climbing.

Tetapi dalam hal ini, para wartawan tersebut diundang untuk memberitakan bentuk protes mereka (Kancana, 2019, p. 188).

Pelibatan awak media dalam kegiatan tersebut diharapkan dapat menjadi cara yang tepat dan cepat dalam menyampaikan pesan-pesan kepedulian masyarakat terhadap alam. Kepada para awak media, mereka berharap perlawanan yang mereka lakukan dapat diketahui oleh semua lapisan masyarakat baik pihak pemerintah maupun perusahaan yang 
Mamad Ahmad dan Asep Supriadi: Konservasi Alam dalam Novel Kekal Karya Jalu...

telah mengambil keuntungan tanpa memperhatikan efek negatif bagi kelangsungan hidup masyarakat.

Perlawanan melalui kegiatan free solo climbing di wilayah Sumatra ini berhasil menarik perhatian organisasi pemerhati lingkungan nasional dan dunia untuk menindaklanjuti protes-protes yang ditujukan kepada perusahan-perusahaan yang telah merusak lingkungan.

\begin{abstract}
Isu "Sadar Kawasan" berhasil menarik perhatian mereka sehingga kabar dari Anang setibanya di Batam, organisasi TRAFFIC yang dibentuk IUCN dan WWF sudah mulai melakukan penyelidikan terhadap perusahaan $\mathrm{C}$ beserta perusahaan-perusahaan yang dinaunginya. Buatku, itu menjadi indikasi bahwa "Sadar Kawasan" telah melakukan terobosannya (Kancana, 2019, p. 230).
\end{abstract}

Isu "Sadar Kawasan" yang digagas oleh konservasionis Sumatra ini berhasil menjadi momentum kebangkitan Alit dan kawan-kawan untuk melanjutkan perjuangan yang sempat tertunda. Respon positif dari organisasi pencinta lingkungan membawa semangat baru bagi Alit dan kawan-kawan untuk melanjutkan perjuangan "Save Ciharus" nya.

Kekuatan "Gerakan Sadar Kawasan" yang telah terbentuk di Sumatra menjadi modal dasar bagi "Save Ciharus" untuk lebih kuat lagi dalam memperjuangkan keutuhan kawasan Cagar Alam Ciharus Kamojang. Gerakan "Save Ciharus" telah membuka mata para penggiat alam bebas/pencinta lingkungan lainnya untuk membantu mengembalikan fungsi kawasan Ciharus sebagai kawasan cagar alam. Berbagai kegiatan dilakukan sebagai wujud upaya pelestarian alam.

Ada kabar bahwa beberapa dari mereka memasang puluhan sengkedan di tengah jalur motor trail guna merestorasi tanah yang telah tergerus habis. Ada juga yang melakukan penutupan pintu hutan menuju kawasan Danau Ciharus. Namun, yang paling menjadi sorotan media lokal adalah adanya sekelompok mapala yang melakukan edukasi terhadap masyarakat yang tinggal di dekat Cagar Alam Kamojang. Mereka menyampaikan bahwa fungsi cagar alam ini untuk penyangga kehidupan, bukan hanya untuk kebutuhan ekonomi. Dengan begitu, masyarakat sekitar akan sadar bahwa SK 25 itu jelas-jelas merugikan mereka (Kancana, 2019, p. 242).

\section{SIMPULAN}

Manusia dan makhluk hidup lainnya memiliki keterkaitan dan ketergantungan satu sama lain. Alam sebagai latar kehidupan manusia dan makhluk hidup lain saling bersimbiosis dalam memenuhi kebutuhan. Manusia dan makhluk hidup lain (binatang) memerlukan alam yang lestari untuk kelangsungan hidup. Begitu pun dengan alam yang membutuhkan sentuhan humanis manusia untuk menjaga kelestarian.

Berdasarkan hasil analisis terhadap novel Kekal karya Jalu Kancana dengan menggunakan kajian ekokritik, penulis memaparkan dua penemuan yang menjadi permasalahan dalam penelitian ini. Pertama, telah terjadi kerusakan lingkungan di Kawasan Cagar Alam Kamojang sebagai akibat dari upaya eksploitasi yang dilakukan oleh perusahaan tambang panas bumi. Kerusakan ini akan mengakibatkan keseimbangan alam terganggu sehingga menimbulkan bencana alam yang akan mengancam kehidupan manusia dan makhluk hidup lain.

Kedua, upaya perlawanan yang dilakukan oleh Alit dan kawan-kawan dengan "Save Ciharus" nya. Perlawanan yang dilakukan lebih bersifat ideologis melalui kampanye "Gerakan Sadar Kawasan". Gerakan ini menyampaikan pesan-pesan tentang pelestarian alam. Kelestarian alam harus senantiasa dijaga karena hutan yang lestari menjadi sumber kehidupan bagi manusia dan makhluk hidup lain. Begitu pun sebaliknya, kerusakan alam akan menjadi sumber bencana bagi kehidupan manusia dan makhluk hidup lain. Selain itu, meraka bersama dengan para penggiat alam dan masyarakat bahu-membahu melakukan reboisasi atau penanaman kembali kawasan hutan sebagai upaya untuk mengembalikan fungsi kawasan hutan sebagaimana mestinya. 
Mamad Ahmad dan Asep Supriadi: Konservasi Alam dalam Novel Kekal Karya Jalu...

\section{DAFTAR PUSTAKA}

Aulia, D., Juanda, \& Saguni, S. S. (2019). Perlawanan Tokoh terhadap Kerusakan Hutan dalam Novel di Kaki Bukit Cibalak Karya Ahmad Tohari dalam Kajian Ekokritik Greg Garrard. Universitas Makasar, $53 \quad$ (9), 1-12. https://doi.org/10.1017/CBO9781107415 324.004

Dewi, N. (2014). Sastra Lingkungan Hidup sebagai Gerakan Sosial. In Prosiding Seminar Bahasa dan Sastra dalam Perspektif Ekologi dan Multiculturalisme. Yogyakarta: Jurusan Bahasa dan Sastra Indonesia, FBS, UNY, hal(pp. 311-319).

Greg, G. (2004). Ecocriticism. London and New York: Routledge.

Harsono, S. (2008). Ekokritik: Kritik Sastra Berwawasan Lingkungan. Kajian Sastra, 32(1), 31-50.

Indonesia, P. R., \& Indonesia, P. R. (n.d.). Undang Undang No. 5 Tahun 1990 Tentang: Konservasi Sumberdaya Alam Hayati dan Ekosistemnya. Jakarta.

Juanda, J. J. (2018). Eksplorasi Nilai Pendidikan Lingkungan Cerpen Daring Republika: Kajian Ekokritik. Jurnal Sosial Humaniora, 11(2), 67. https://doi.org/10.12962/j24433527.v0i0. 4331

Kancana, J. (2019). Kekal. Yogyakarta: Buku Mojok.

Laily, N. (2015). Konservasi Alam dalam Novel Baiat Cinta Di Tanah Baduy Karya Uten Sutendy (Kajian Ekokritik Greg Garrard). Dialektika, 5(15), 131-148. https://doi.org/10.1192/bjp.112.483.211a

Uniawati. (2014). Nelayan di Lautan Utara: Sebuah Kajian Ekokritik. Kandai, 10(2), 246-257.

Yasser, M. (2014). Etika Lingkungan dalam Perspektif Teori Kesatuan Wujud Teosofi Transenden. Kanz Philosophia: A Journal for Islamic Philosophy and Mysticism, 4(1), 47-60. 